\title{
A simple method for preparing superconducting FeSe pellets without sealing in evacuated silica tubes
}

\section{Grivel, Jean-Claude}

\section{Published in:}

Ceramics International

Link to article, DOI:

10.1016/j.ceramint.2017.05.280

Publication date:

2017

Document Version

Peer reviewed version

Link back to DTU Orbit

Citation (APA):

Grivel, J-C. (2017). A simple method for preparing superconducting FeSe pellets without sealing in evacuated silica tubes. Ceramics International, 43(14), 11474-11480. https://doi.org/10.1016/j.ceramint.2017.05.280

\section{General rights}

Copyright and moral rights for the publications made accessible in the public portal are retained by the authors and/or other copyright owners and it is a condition of accessing publications that users recognise and abide by the legal requirements associated with these rights.

- Users may download and print one copy of any publication from the public portal for the purpose of private study or research.

- You may not further distribute the material or use it for any profit-making activity or commercial gain

- You may freely distribute the URL identifying the publication in the public portal

If you believe that this document breaches copyright please contact us providing details, and we will remove access to the work immediately and investigate your claim 


\title{
A simple method for preparing superconducting FeSe pellets without sealing in evacuated silica tubes
}

\author{
J.-C. Grivel \\ Department of Energy Conversion and Storage, Technical University of Denmark, \\ 4000-Roskilde, Denmark
}

\begin{abstract}
Superconducting tetragonal FeSe pellets were made by reacting mixtures of elemental $\mathrm{Fe}$ and $\mathrm{Se}$ powders in argon atmosphere without sealing in evacuated silica tubes. A simple tube furnace has been used. Although the tube's material consisted of quartz, an alumina tube could be used as well. X-ray pure samples with onset of superconducting transition between $8.0 \mathrm{~K}$ and $8.5 \mathrm{~K}$ were obtained under specific heat treatment conditions. Residual, unreacted Fe particles could be virtually eliminated through prolonged annealing. A key factor for the synthesis of good samples consists in using processing parameters that minimize Se losses.
\end{abstract}

Keywords: FeSe, chalcogenides, heat treatment, processing parameters

\section{Corresponding author: Jean-Claude Grivel}

jean@dtu.dk 


\section{Introduction}

The superconducting, tetragonal form of the FeSe phase is, from a structural point of view, the simplest representative of the recently discovered family of iron based superconductors [1,2]. In spite of its relatively low critical temperature of about $8.5 \mathrm{~K}$, this superconductor is an interesting candidate for the manufacture of wires that could produce large magnetic fields after winding [35].

However, the synthesis of single-phase FeSe polycrystalline samples is not straightforward. This is due to several factors linked to the low melting and boiling temperatures of $\mathrm{Se}\left(221{ }^{\circ} \mathrm{C}\right.$ and $685{ }^{\circ} \mathrm{C}$ respectively), compared with the melting point of $\mathrm{Fe}\left(1535^{\circ} \mathrm{C}\right)$, combined with the fact that the superconducting tetragonal FeSe phase is unstable above $457^{\circ} \mathrm{C}$ [6]. Additionally, the ease of oxidation of $\mathrm{Fe}$ and Se during high temperature processing as well as the sensitivity of FeSe to air exposure also contribute to this difficulty. The fact that the Fe-Se binary system contains intermetallic compounds with compositions close to that of the FeSe superconducting phase (i.e. $\mathrm{Fe}_{7} \mathrm{Se}_{8}$ and hexagonal $\mathrm{FeSe}$ ) also means that slight deviations in stoichiometry can lead to a large proportion of impurities in the samples.

So far, most reported preparation conditions involve sealing in evacuated quartz ampoules, heating most often well above the temperature, below which tetragonal FeSe is stable, followed or not by annealing at $300{ }^{\circ} \mathrm{C} \leq \mathrm{T} \leq 460{ }^{\circ} \mathrm{C}$ [7-22]. In some cases, several heat treatments are performed, requiring re-sealing in new evacuated ampoules [14-22]. Although this processing route usually results in good samples, it is time and resources consuming, because the silica tubes are generally broken and disposed of at the end of each heat treatment, and thus not optimized for potential large-scale production. Furthermore, it has been reported that reaction in silica tubes can result in the formation of silicide impurities [20]. 
The present work was undertaken to explore the possibility of using a simpler technology. By merely wrapping pellets consisting of a mixture of Fe and Se powders into a Ti foil and avoiding too high reaction temperatures, it has been found that X-ray pure samples with a $T_{c}$ onset of 8.5 $\mathrm{K}$ can be prepared if proper conditions are used.

\section{Experimental details}

The starting reagents consisted of Fe powder $(99.9 \%$ purity, <10 $\mu \mathrm{m})$ and Se powder (99.999\%, -200 mesh), both from Alfa Aesar. They were mixed in a Fe : Se = $1.0: 0.975$ atomic ratio and homogenised in a shaker (Bachofen $\mathrm{AG}$ ) in polyethylene jars for 24 hours with $\mathrm{NiO}$ balls ( 2 pieces of $4 \mathrm{~g}$ for $2 \mathrm{~g}$ powder). After mixing, the powders were pressed into pellets ( $1 \mathrm{~g}$ powder, $12 \mathrm{~mm}$ diameter under a pressure of $1.8 \mathrm{kbar})$. The pellets were then wrapped into Ti foils of $32 \mu \mathrm{m}$ thickness that act as oxygen getter and reduce the risk of Se losses during heat treatment. The samples were finally inserted in a tubular furnace and reacted under argon atmosphere $\left(<0.5 \mathrm{ppm}\right.$ residual $\left.\mathrm{O}_{2}\right)$. All manipulations except pressing were performed inside a glove-box filled with Ar gas.

The sample names reflect the heat treatments. For example "120-400-600" denotes that a heating rate of $120{ }^{\circ} \mathrm{C} / \mathrm{h}$ was applied up to the reaction temperature of $400{ }^{\circ} \mathrm{C}$ and that the sample was kept at this temperature during 600 minutes $(10 \mathrm{~h})$. "120-700-60-400-6000" is equivalent to heating at $120^{\circ} \mathrm{C} / \mathrm{h}$ up to $700^{\circ} \mathrm{C}, 60$ minutes reaction, followed to cooling to 400 ${ }^{\circ} \mathrm{C}$ and 6000 minutes annealing at $400{ }^{\circ} \mathrm{C}$. Finally, the plus sign $(+)$ inserted in the sample name separates two heat treatments, between which the pellet was ground and pressed again. The exact heat treatment procedure is specified for each set of preparation conditions in the following section and is summarized in Table 1. 
XRD patterns were recorded in a Bruker Robot X-ray diffractometer with $\mathrm{CuK} \alpha$ radiation $(\lambda=$ $1.5406 \AA$ A) on powdered samples after the end of the heat treatment. The microstructure of the samples and the composition of the various phases present after reaction were studied by means of scanning electron microscopy (SEM) in a table-top TM3000 microscope from HITACHI equipped with a QUANTAX 70 EDS analyser. The relative accuracy of the compositions obtained by EDS is of $2 \%$. The critical temperature $\left(\mathrm{T}_{\mathrm{c}}\right)$ was determined as the onset of the diamagnetic transition measured in a vibrating sample magnetometer (VSM) setup in a CRYOGENIC Ltd Mini-CFMS with an applied dc-field of $10 \mathrm{mT}$.

\section{Results and Discussion}

Figure 1 shows the XRD patterns of three samples reacted at $400{ }^{\circ} \mathrm{C}$ for $1 \mathrm{~h}$, but heated to the target temperature at different rates: $300{ }^{\circ} \mathrm{C} / \mathrm{h}, 120^{\circ} \mathrm{C} / \mathrm{h}$ and $30{ }^{\circ} \mathrm{C} / \mathrm{h}$. In all cases, the tetragonal form of FeSe is the majority phase. It coexists with a significant amount of another Fe selenide characterized by strong diffraction peaks at $32.3^{\circ}, 42.1^{\circ}$ and $50.3^{\circ}(2 \theta)$. These could belong to either $\mathrm{Fe}_{7} \mathrm{Se}_{8}$ or to the hexagonal form of $\mathrm{FeSe}$. According to the phase diagram assessed by Okamoto [6], tetragonal FeSe is stable up to $457^{\circ} \mathrm{C}$ and decomposes peritectically into $\alpha$-Fe and hexagonal FeSe above this temperature. Since the reaction temperature was lower than this transition point, it is unlikely that the tetragonal FeSe has formed by reaction between $\alpha$-Fe and hexagonal FeSe during cooling, as it is the case in processes involving reaction at $\mathrm{T}>457^{\circ} \mathrm{C}$ [722].

According to an in-situ phase formation study [23], tetragonal FeSe readily forms from the pure elements via a series of intermediate compounds with increasing Fe:Se atomic ratio, i.e. $\mathrm{FeSe}_{2}, \mathrm{Fe}_{3} \mathrm{Se}_{4}$ and $\mathrm{Fe}_{7} \mathrm{Se}_{8}$ during a heating ramp of $120{ }^{\circ} \mathrm{C} / \mathrm{h}$, similar to that used for one of the present samples, and under these conditions it was found that tetragonal FeSe had formed before 
reaching $400^{\circ} \mathrm{C}$. However, the overall stoichiometry in [23] was more Se deficient $\left(\mathrm{FeSe}_{0.9}\right)$ and the powders tightly packed in a $\mathrm{Cu} / \mathrm{Nb}$ metal sheath. In the present case, a lower degree of compaction may have resulted in slower reaction kinetics. This, coupled with the higher Se content, could explain the coexistence of tetragonal FeSe, $\alpha-\mathrm{Fe}$ and hexagonal $\mathrm{FeSe} / \mathrm{Fe}_{7} \mathrm{Se}_{8}$. It should be noted that the coexistence of 3 phases in this area of the Fe-Se binary system indicates that the phase assembly is not that of an equilibrium state. Using a slower heating rate of $30{ }^{\circ} \mathrm{C} / \mathrm{h}$ does not result in significant improvements.

Reaction kinetics limited effects are however clearly at play in the sample heated at a rate of $300{ }^{\circ} \mathrm{C} / \mathrm{h}$, for which several additional impurity phases including $\mathrm{FeSe}_{2}, \mathrm{Fe}_{3} \mathrm{Se}_{4}$ and $\mathrm{Fe}_{7} \mathrm{Se}_{8}$ are seen in the XRD pattern, while the intensity of the $\alpha$-Fe phase peak at $44.7^{\circ}$ is enhanced.

While none of these samples is monophasic, superconductivity was found in all of them as shown in Figure 2. A transition with onset at 7.0 to $7.5 \mathrm{~K}$ takes places without dependence on the heating rate. The normal state is characterized by a positive magnetization that increases for increasing heating rate. This effect is probably linked to the increasing amount of residual $\alpha$-Fe phase in the samples prepared with faster heating rates. This contribution is large enough for preventing the magnetization from taking negative values down to $3.5 \mathrm{~K}$. It can however be noted that the normal state magnetization values of these samples are not especially high compared with samples made by conventional techniques, since a single crystal was reported to have a magnetization of $1.210^{-4} \mathrm{emu} / \mathrm{g}$ just above the superconducting transition [13].

SEM images of the three samples are shown in Figure 3 with two different magnifications. The overall views (Figures 3a-c) show that the samples are highly porous. Higher magnification images (Figure 3d to $\mathrm{f}$ ) reveal that the structure is inhomogeneous with particles having 
diameters reaching up to $10 \mu \mathrm{m}$ embedded in a coating that may have been liquid at some point during the heat treatment.

Figure 4 presents EDS elemental maps of sample 120-400-60. It appears that the embedded particles are Fe-rich. In fact, the largest among them do not contain Se in contrast to the small ones, in which Se was also detected. Additionally, there is often an empty space between the Ferich embedded particles and the surrounding matrix. All these features were observed in all three samples. A possible explanation for this microstructure is that Se first melts, providing a liquid phase that coats the Fe particles. Se then diffuses into the Fe grains, forming Fe-Se phases with increasing Se content. FeSe being the most Se-rich compound in the Fe-Se system, this process naturally proceeds up to that phase. However, local heterogeneities in the Fe-Se distribution as well as reaction kinetics parameters and insufficient reaction time can contribute to incomplete reaction and therefore $\mathrm{Fe}$ and $\mathrm{Fe}$-rich core particles remain embedded in a Fe-Se crust at the end of the heat treatment. During cooling, differential contraction may be the origin of the void space between the core particles and the matrix.

Based on the results published in [23], the tetragonal FeSe phase forms essentially above 350 ${ }^{\circ} \mathrm{C}$ during the heating stage. The intermediate stage phase between $\mathrm{Fe}_{3} \mathrm{Se}_{4}$ and tetragonal $\mathrm{FeSe}$ is most probably the phase denoted as $\delta$ in [6] (hexagonal FeSe), which upon cooling may result in the formation of $\mathrm{Fe}_{7} \mathrm{Se}_{8}$.

Se loss by evaporation is also likely to disturb the homogeneity of the samples by resulting in modifications of the overall and local stoichiometry. If the initial reaction kinetics between liquid Se and solid Fe is slower than the melting rate of Se, which can reasonably be expected, using a faster heating rate will extend the time during which liquid Se is present and can evaporate. This hypothesis was confirmed by large area EDS analyses (average over several $20.000 \mu \mathrm{m}^{2}$ frames) 
showing average compositions with $2 \%$ relative accuracy of $\mathrm{Fe}_{1.00} \mathrm{Se}_{0.98}$ for the sample heated at $30^{\circ} \mathrm{C} / \mathrm{h}$ and $\mathrm{Fe}_{1.00} \mathrm{Se}_{0.99}$ at $120^{\circ} \mathrm{C} / \mathrm{h}$, but $\mathrm{Fe}_{1.00} \mathrm{Se}_{0.84}$ for $300{ }^{\circ} \mathrm{C} / \mathrm{h}$. This provides evidence that a fast heating rate should be avoided under reaction conditions such as those used in the present study.

The effect of prolonging the reaction time at $400{ }^{\circ} \mathrm{C}$ is shown in Figs. 5 and 6 , which respectively contain the XRD patterns and magnetization measurements recorded on samples heated to $400^{\circ} \mathrm{C}$ at a rate of $120^{\circ} \mathrm{C} / \mathrm{h}$, but maintained at $400{ }^{\circ} \mathrm{C}$ for $1 \mathrm{~h}, 10 \mathrm{~h}$ or $100 \mathrm{~h}$. Clearly, longer dwell times improve the phase purity of the samples. The diffraction peaks due to $\alpha$-Fe and the hexagonal $\mathrm{FeSe}$ (or $\mathrm{Fe}_{7} \mathrm{Se}_{8}$ ) phases are much less intense after $10 \mathrm{~h}$ reaction and essentially disappear from the patterns for the sample treated for $100 \mathrm{~h}$ at $400{ }^{\circ} \mathrm{C}$ (Fig.5). Based on X-ray diffraction analysis, this last sample appears clearly purer than many samples synthesized in sealed, evacuated silica ampoules $[17,19,21,22]$ and even of some crushed single crystals [13] that contain a detectable amount of the hexagonal impurity. The transition to the superconducting state (Fig.6) becomes sharper and the onset increases to $8.5 \mathrm{~K}$. The normal state magnetization becomes close to zero for increasing dwell time, as can be expected from the decreasing amount of unreacted $\mathrm{Fe}$ in the samples reacted for more than $1 \mathrm{~h}$. These features reflect clear improvements of the samples as a result of longer reaction time.

The overall microstructure of the samples is not modified significantly at first sight by the prolonged reaction time as illustrated in Figs. $7 \mathrm{a}$ and $\mathrm{b}$ that compare the samples reacted during $1 \mathrm{~h}$ and $100 \mathrm{~h}$. The porosity is comparable and core particles surrounded by a matrix can still be distinguished. However, EDS elemental maps (Figs.7 c and d) reveal a more homogeneous distribution of $\mathrm{Fe}$ and $\mathrm{Se}$ in the $100 \mathrm{~h}$ reacted sample as compared with Fig.4, indicating that $\mathrm{Fe}$ and Se inter-diffusion proceeded to a greater extent. This is in agreement with the XRD patterns 
and in clear contrast with the samples reacted during $1 \mathrm{~h}$ only (Fig.4). The average composition determined by EDS over large areas is $\mathrm{FeSe}_{0.98}$ after $10 \mathrm{~h}$ and $\mathrm{FeSe}_{0.99}$ after $100 \mathrm{~h}$ reaction, showing that the prolonged treatment at $400{ }^{\circ} \mathrm{C}$ does not induce significant Se loss.

FeSe superconductors are often prepared by heating the elemental mixture first above the stability temperature of tetragonal $\mathrm{FeSe}$, i.e. around $700{ }^{\circ} \mathrm{C}$ and letting it cool at various rates followed or not by annealing below $457^{\circ} \mathrm{C}$. Fig. 8 shows the XRD patterns of samples reacted at $700{ }^{\circ} \mathrm{C}$ for $1 \mathrm{~h}$ or $10 \mathrm{~h}$ and furnace cooled to room temperature, as well as one that was reacted at $700{ }^{\circ} \mathrm{C}$ for $1 \mathrm{~h}$, cooled to $400{ }^{\circ} \mathrm{C}$ at $120^{\circ} \mathrm{C} / \mathrm{h}$, annealed at that temperature for $100 \mathrm{~h}$ and finally furnace cooled. The two samples that were not annealed at $400{ }^{\circ} \mathrm{C}$ show the presence of $\alpha$-Fe and of peaks that again correspond either to hexagonal $\mathrm{FeSe}$ or $\mathrm{Fe}_{7} \mathrm{Se}_{8}$. The fact that the phase assembly is not significantly different after $1 \mathrm{~h}$ or $10 \mathrm{~h}$ reaction at $700{ }^{\circ} \mathrm{C}$ indicates that the cooling rate is probably the most important parameter controlling the final phase distribution in these samples. In contrast, the sample that was annealed at $400{ }^{\circ} \mathrm{C}$ is "X-ray pure" tetragonal FeSe. The magnetic susceptibility data presented in Fig.9 show that the sample annealed at 400 ${ }^{\circ} \mathrm{C}$ exhibits a superconducting transition comparable to that found for the sample simply reacted at $400{ }^{\circ} \mathrm{C}$ for $100 \mathrm{~h}$ (Fig. 6), with an onset at $8.5 \mathrm{~K}$. On the other hand, the two samples that were not annealed at $400{ }^{\circ} \mathrm{C}$ present lower $\mathrm{T}_{\mathrm{c}}$ 's and a weaker superconducting signal. Furthermore, the sample reacted at $700{ }^{\circ} \mathrm{C}$ during $10 \mathrm{~h}$ without annealing has a stronger positive magnetisation in the normal state. Like for the previous series of samples, this could be linked to a larger proportion of unreacted Fe. The intensity of the Fe reflection at $2 \theta=44.6^{\circ}$ in the XRD patterns is slightly more intense after $10 \mathrm{~h}$ reaction at $700{ }^{\circ} \mathrm{C}$ than just $1 \mathrm{~h}$. Furthermore, the overall stoichiometry measured by EDS on large areas reveals $\mathrm{FeSe}_{0.98}$ and $\mathrm{FeSe}_{0.87}$ compositions for the 
$1 \mathrm{~h}$ and $10 \mathrm{~h}$ reacted samples respectively, confirming that Se losses take place during long annealing at $700{ }^{\circ} \mathrm{C}$.

A SEM image of the polished cross-section of the sample reacted at $700{ }^{\circ} \mathrm{C}$ for $1 \mathrm{~h}$ and annealed at $400{ }^{\circ} \mathrm{C}(120-700-60-400-6000)$ is shown in Fig. 10. It exhibits a microstructure similar to those of samples reacted at $400{ }^{\circ} \mathrm{C}$ (Figs. 3 and 7), especially sample (120-400-6000) with only few residual Fe particles embedded in a FeSe coating layer. Many holes are observed within the FeSe matrix. They probably mark the position of Fe particles that reacted with the Serich $\mathrm{Fe}-\mathrm{Se}$ surrounding matrix during the prolonged annealing at $400{ }^{\circ} \mathrm{C}$.

Two-step heat treatments with intermediate grinding and re-compacting were also tested. As shown in Fig. 11 (a and d), this results in a significant decrease of the porosity, especially for the case where a pellet was initially reacted at $700{ }^{\circ} \mathrm{C}$ for $1 \mathrm{~h}$, followed by simple annealing at $400{ }^{\circ} \mathrm{C}$ during $100 \mathrm{~h}$ (120-700-60+120-400-6000). Unreacted Fe particles are however still visible in the EDS maps (Figs. $11 \mathrm{~b}$ and c). Introducing an additional reaction stage at $700{ }^{\circ} \mathrm{C}$ after recompaction and prior to a final annealing at $400{ }^{\circ} \mathrm{C}$ is detrimental for the density of the pellet as revealed by the higher porosity of this sample (Figs. $11 \mathrm{~d}-\mathrm{f}$ ). Unreacted Fe particles are still present and seem to be generally larger than without this second heat treatment at $700{ }^{\circ} \mathrm{C}$. The overall composition of this sample is estimated to $\mathrm{FeSe}_{0.95}$, meaning that more Se has been lost in comparison with the sample that was only subjected to the first part of the heat treatment, i.e. single reaction at $700{ }^{\circ} \mathrm{C}$ for $1 \mathrm{~h}(120-700-60)$. Se loss might also have been taking place in the (120-700-60+120-400-6000) sample, but to a lower extent and the EDS value of $\mathrm{FeSe}_{0.97}$ is basically similar to that determined after the first part of this heat treatment $\left(\mathrm{FeSe}_{0.98}\right.$ in (120700-60)). The fact that the composition of the samples subjected to two-step heat treatments has become Se depleted is confirmed by the XRD patterns (Fig.12) showing the emergence of a 
reflection due to metallic $\mathrm{Fe}$, as well as by the enhanced positive magnetization of the samples above $\mathrm{T}_{\mathrm{c}}$ (Fig.13).

It therefore appears that good quality tetragonal FeSe samples, in terms of phase purity and superconducting transition, can be readily synthesized using a simple, one-step heat treatment in Ar atmosphere without need for sealing in evacuated silica ampoules. The best results are obtained when Se losses are minimized by using a relatively low reaction temperature and a slow heating rate. The mechanism responsible for the degradation of phase purity as well as superconducting transition when the FeSe samples are ground, repressed and merely annealed at $400{ }^{\circ} \mathrm{C}$ is not clear. Further optimization work will be necessary to avoid this drawback and to take advantage of the significantly increase sample density.

\section{Conclusion}

The synthesis of superconducting FeSe by a simple technique that does not require sealing in evacuated silica tubes is possible provided careful control of key processing variables. In particular, it has been demonstrated that the heating rate must be slow enough, whereas the reaction temperature has to be kept relatively low, both factors contributing to limiting Se losses that would lead to a departure from the initial stoichiometry. For a reaction temperature of 400 ${ }^{\circ} \mathrm{C}$, a dwell time of $100 \mathrm{~h}$ leads to a magnetic $\mathrm{T}_{\mathrm{c}}$ onset of $8.5 \mathrm{~K}$ and a negligible amount of unreacted Fe. The phase purity of this sample is comparable to some of the best samples produced in evacuated, sealed silica ampoules $[7,8,16]$. A further advantage of using a reaction temperature of $400{ }^{\circ} \mathrm{C}$ only is that the Ti foil used for wrapping the samples is only slightly oxidized by the residual oxygen present in the Ar atmosphere and can be therefore be reused several times before becoming brittle. The high porosity of the samples can nevertheless be a clear disadvantage in view of applications as it would drastically limit the achievable transport 
critical current density. The sample density can be greatly improved by two-step heat treatments, but these appear to worsen the phase purity. This problem might be circumvented by alternative one-step treatments involving for example hot pressing and/or further optimization of the processing conditions. 


\section{References}

[1] Kamihara Y., Watanabe T., Hirano M. and Hosono H., Iron-based layered superconductor $\mathrm{La}\left[\mathrm{O}_{1-\mathrm{x}} \mathrm{F}_{\mathrm{x}}\right] \mathrm{FeAs}(\mathrm{x}=0.05-0.12)$ with $\mathrm{T}_{\mathrm{c}}=26 \mathrm{~K}$, J. Am. Chem. Soc. 130 (2008) $3296-3297$

[2] Si Q.M., Yu R. and Abrahams E., High-temperature superconductivity in iron pnictides and chalcogenides, Nature Reviews Materials 1 (2016) 16017

[3] Ozaki T., Deguchi K., Mizuguchi Y., Kawasaki Y., Tanaka T., Yamaguchi T., Kumakura H. and Takano Y., Fabrication of binary FeSe superconducting wires by diffusion process, J. Appl. Phys. 111 (2012) 112620

[4] Vlasenko V., Pervakov K., Pudalov V., Prudkoglyad V., Berbentsev V., Gavrilkin S and Eltsev Y, Effect of heat treatment on superconducting properties of FeSe wire fabricated by PIT method, J. Phys. Conf. Ser. 507 (2014) 022044

[5] Feng J.Q., Zhang S.N., Liu J.X., Li C.S., Ma X.B. and Zhang P.X., Fabrication of FeSe superconducting tapes with high-energy ball milling aided PIT process, Mater. Lett. 170 (2016) $31-34$

[6] Okamoto H., The Fe-Se (iron-selenium) system, J. Phase Equilibria 12, (1991) 383 - 389

[7] Pomjakushina E., Conder K., Pomjakushin V., Bendele M. and Khasanov R., Synthesis, crystal structure, and chemical stability of the superconductor FeSe ${ }_{1-x}$, Phys. Rev. B 80 (2009) 024517

[8] Williams A.J., McQueen T.M. and Cava R.J., The stoichiometry of FeSe, Solid State Commun. 149 (2009) $1507-1509$

[9] Grønvold F., Heat capacities and thermodynamic properties of the iron selenides $\mathrm{Fe}_{1.04} \mathrm{Se}$, $\mathrm{Fe}_{7} \mathrm{Se}_{8}$ and $\mathrm{Fe}_{3} \mathrm{Se}_{4}$ from 298 to 1050K, Acta Chem. Scand. 22 (1968) $1219-1240$ 
[10] Hägg G. and Kindström A.-L., Röntgenuntersuchung am System Eisen-Selen, Z. Physic. Chem. B22 (1933) 453 - 464

[11] McQueen T.M., Huang Q., Ksenofontov V., Felser C., Xu Q., Zandbergen H., Hor Y.S., Allred J., Williams A.J., Qu D., Checkelsky J., Ong N.P. and Cava R.J., Extreme sensitivity of superconductivity to stoichiometry in $\mathrm{Fe}_{1+\delta} \mathrm{Se}$, Phys. Rev. B 79 (2009) 014522

[12] Cui Y.J., Wang X.F., Li P.Y., Chen Y.L. and Zhao Y., Effect of the FeSe precursor on the superconductivity of $\mathrm{K}_{\mathrm{x}} \mathrm{Fe}_{2-\mathrm{y}} \mathrm{Se}_{2}$, J. Supercond. Nov. Magn. 29 (2016) 2771 - 2775

[13] Maheshwari P.K., Joshi L.M., Gahtori B., Srivastava A.K., Gupta A., Patnaik S.P. and Awana V.P.S., Flux free growth of superconducting FeSe single crystals, Mater. Res. Express 3 (2016) 076002

[14] Jain B.K., Singh A.K. and Chandra K., An investigation of binary system Fe-Se, J. Phys. F 8 (1978) $2625-2630$

[15] Yeh K.W., Hsu H.C., Huang T.W., Wu P.M., Huang Y.L., Chen T.K., Luo J.Y. and Wu M.K., Se and Te doping study of the FeSe superconductor, J. Phys. Soc. Jpn. 77 (2008) Suppl. C $19-22$

[16] Onar K. and Yakinci M.E., Solid state synthesis and characterization of bulk beta-FeSe superconductors, J. Alloys Compounds 620 (2015) 210 - 216

[17] Muralidhar M., Furutani K., Kumar D., Koblischka M.R., Ramachandra Rao M.S. and Murakami M., Improved critical current densities in bulk FeSe superconductor using ball milled powders and high temperature sintering, Phys. Stat. Sol. A 213 (2016) $3214-3220$

[18] Sklyarova A., Tewari G.C., Lindén J., Rautama E.-L. And Karpinnen M., Evolution of the internal magnetic field in chalcogenide superconductors $F e T e_{1-\mathrm{x}} \mathrm{S}_{\mathrm{x}}$ for various $\mathrm{x}$ values, $\mathrm{J}$. Magn. Magn. Mater. 357 (2014) 82 - 86 
[19] Nazarova E., Balchev N., Nenkov K., Buchkov K, Kovacheva D., Zahariev A. and Fuchs G, Improvement of the superconducting properties of polycrystalline FeSe by silver addition, Supercond. Sci. Technol. 28 (2015) 125013

[20] Hsu F.C., Luo J.Y., Yeh K.W., Chen T.K., Huang T.W., Wu P.M., Lee Y.C., Huang Y.L., Chu Y.Y., Yan D.C. and Wu M.K., Superconductivity in the PbO-type structure alphaFeSe, Proceedings of the National Academy of Sciences of the United States of America 105 (2008) $14262-14264$

[21] Yadav A.K., Thakur A.D. and Tomy C.V., Enhanced superconducting properties in $\mathrm{FeCr}_{\mathrm{x}} \mathrm{Se}$, Solid State Commun. 151 (2011) 557 - 560

[22] Sudesh, Rani S. and Varma G.D., Effect of Sb and Si doping on the superconducting properties of $\mathrm{FeSe}_{0.9}$, Physica C 485 (2013) 137 - 144

[23] Grivel J.-C., Wulff A.C., Zhao Y., Andersen N.H., Bednarcik J. and Zimmermann M.v., In situ observation of the formation of FeSe, Supercond. Sci. Technol. 24 (2011) 015007 


\section{Figure captions}

Figure 1: XRD patterns of samples reacted at $400^{\circ} \mathrm{C}$ during $1 \mathrm{~h}$, using different heating rates: 30 ${ }^{\circ} \mathrm{C} / \mathrm{h}$ (30-400-60), $120{ }^{\circ} \mathrm{C} / \mathrm{h}(120-400-60)$ and $300{ }^{\circ} \mathrm{C} / \mathrm{h}(300-400-60) .9$ FeSe (tetragonal), O FeSe (hexagonal) or $\mathrm{Fe}_{7} \mathrm{Se}_{8}, \square \mathrm{Fe}_{3} \mathrm{Se}_{4}, \mathrm{FeSe}_{2}, \mathbf{\alpha}-\mathrm{Fe}$.

Figure 2: Magnetic susceptibility of samples reacted at $400^{\circ} \mathrm{C}$ during $1 \mathrm{~h}$, using different heating rates: $30{ }^{\circ} \mathrm{C} / \mathrm{h} \quad(30-400-60), \quad 120{ }^{\circ} \mathrm{C} / \mathrm{h} \quad(120-400-60)$ and $300{ }^{\circ} \mathrm{C} / \mathrm{h} \quad(300-400-60)$. The measurements were performed with an applied DC field of $10 \mathrm{mT}$.

Figure 3: SEM images (backscattering mode) of polished crossed sections of the samples reacted at $400^{\circ} \mathrm{C}$ during $1 \mathrm{~h}$, using different heating rates: $30{ }^{\circ} \mathrm{C} / \mathrm{h}$ (a and d), $120{ }^{\circ} \mathrm{C} / \mathrm{h}(\mathrm{b}$ and e) and $300^{\circ} \mathrm{C} / \mathrm{h}(\mathrm{c}$ and $\mathrm{f})$.

Figure 4: EDS maps showing the distribution of $\mathrm{Se}$ and $\mathrm{Fe}$ in the samples reacted at $400^{\circ} \mathrm{C}$ during $1 \mathrm{~h}$, using a heating rate of $120^{\circ} \mathrm{C} / \mathrm{h}$.

Figure 5: $\mathrm{XRD}$ patterns of samples reacted at $400^{\circ} \mathrm{C}$ for $1 \mathrm{~h}(120-400-60), 10 \mathrm{~h}(120-400-600)$ and $100 \mathrm{~h}$ (120-400-6000). The heating rate was $120^{\circ} \mathrm{C} / \mathrm{h}$ for all samples. FeSe (tetragonal), O FeSe (hexagonal) or $\mathrm{Fe}_{7} \mathrm{Se}_{8}, \diamond \alpha-\mathrm{Fe}$.

Figure 6: Magnetic susceptibility of samples reacted at $400^{\circ} \mathrm{C}$ for $1 \mathrm{~h}(120-400-60)$, $10 \mathrm{~h}(120-$ 400-600) and $100 \mathrm{~h}(120-400-6000)$. The heating rate was $120{ }^{\circ} \mathrm{C} / \mathrm{h}$ for all samples. The measurements were performed with an applied DC field of $10 \mathrm{mT}$.

Figure 7: SEM images (backscattering mode) of polished cross-sections of the samples reacted at $400^{\circ} \mathrm{C}$ for $1 \mathrm{~h}(\mathrm{a})$ and $100 \mathrm{~h}(\mathrm{~b})$, both with a heating rate of $120^{\circ} \mathrm{C} / \mathrm{h}$ as well as EDS elemental maps of the sample reacted for $100 \mathrm{~h}(\mathrm{c}$ and d).

Figure 8: $\mathrm{XRD}$ patterns of samples reacted at $700^{\circ} \mathrm{C}$ for $1 \mathrm{~h}(120-700-60)$ and $10 \mathrm{~h}(120-700-$ 600 ), as well as at $700^{\circ} \mathrm{C}$ for $1 \mathrm{~h}$ followed by annealing at $400^{\circ} \mathrm{C}$ for $100 \mathrm{~h}$ with a cooling rate of 
$120^{\circ} \mathrm{C} / \mathrm{h}$ between $700^{\circ} \mathrm{C}$ and $400^{\circ} \mathrm{C}(120-700-60-400-6000)$. The heating rate was $120{ }^{\circ} \mathrm{C} / \mathrm{h}$ for all samples and furnace cooling was used at the end of the heat treatments. FeSe (tetragonal), FeSe (hexagonal) or $\mathrm{Fe}_{7} \mathrm{Se}_{8}, \diamond \alpha-\mathrm{Fe}$.

Figure 9: Magnetic susceptibility of samples reacted at $700^{\circ} \mathrm{C}$ for $1 \mathrm{~h}(120-700-60)$ and $10 \mathrm{~h}$ (120-700-600), as well as at $700^{\circ} \mathrm{C}$ for $1 \mathrm{~h}$ followed by annealing at $400^{\circ} \mathrm{C}$ for $100 \mathrm{~h}$ with a cooling rate of $120^{\circ} \mathrm{C} / \mathrm{h}$ between $700^{\circ} \mathrm{C}$ and $400^{\circ} \mathrm{C}(120-700-60-400-6000)$. The heating rate was $120{ }^{\circ} \mathrm{C} / \mathrm{h}$ for all samples and furnace cooling was used at the end of the heat treatments. The measurements were performed with an applied DC field of $10 \mathrm{mT}$.

Figure 10: SEM image (backscattering mode) of the polished cross-section of the sample reacted at $700^{\circ} \mathrm{C}$ for $1 \mathrm{~h}$ followed by annealing at $400^{\circ} \mathrm{C}$ for $100 \mathrm{~h}$ without intermediate grinding (120-700-60-400-6000).

Figure 11: SEM images (backscattering mode) and EDS elemental maps of polished crosssections of the samples reacted according to a two-step process. (a-c) $700^{\circ} \mathrm{C}$ for $1 \mathrm{~h}$ followed by $400^{\circ} \mathrm{C}$ for $100 \mathrm{~h}(120-700-60+120-400-6000)$; (d-f) $700^{\circ} \mathrm{C}$ for $1 \mathrm{~h}$ followed by $700^{\circ} \mathrm{C}$ for $1 \mathrm{~h}$ with annealing at $400^{\circ} \mathrm{C}$ for $100 \mathrm{~h}(120-700-60+120-700-60-400-6000)$.

Figure 12: XRD patterns of samples reacted according to a two-step process: $700^{\circ} \mathrm{C}$ for $1 \mathrm{~h}$ followed by $400^{\circ} \mathrm{C}$ for $100 \mathrm{~h}(120-700-60+120-400-6000) ; 700^{\circ} \mathrm{C}$ for $1 \mathrm{~h}$ followed by $700^{\circ} \mathrm{C}$ for $1 \mathrm{~h}$ with annealing at $400^{\circ} \mathrm{C}$ for $100 \mathrm{~h}(120-700-60+120-700-60-400-6000)$, compared with the XRD pattern of the single-step preparation route with reaction at $700^{\circ} \mathrm{C}$ and annealing at $400^{\circ} \mathrm{C}$ for $100 \mathrm{~h}$ without intermediate grinding (120-700-60-400-6000). $\bigcirc \mathrm{FeSe}$ (tetragonal), $\boldsymbol{\nabla} \mathrm{Fe}_{3} \mathrm{O}_{4}$, $\alpha-\mathrm{Fe}$. 
Figure 13: Magnetic susceptibility of samples reacted according to a two-step process: $700^{\circ} \mathrm{C}$ for $1 \mathrm{~h}$ followed by $400^{\circ} \mathrm{C}$ for $100 \mathrm{~h}(120-700-60+120-400-6000) ; 700^{\circ} \mathrm{C}$ for $1 \mathrm{~h}$ followed by $700^{\circ} \mathrm{C}$ for $1 \mathrm{~h}$ with annealing at $400^{\circ} \mathrm{C}$ for $100 \mathrm{~h}(120-700-60+120-700-60-400-6000)$, compared with the data from the single-step preparation route with reaction either at $700^{\circ} \mathrm{C}$ and annealing at $400^{\circ} \mathrm{C}$ for $100 \mathrm{~h}$ without intermediate grinding (120-700-60-400-6000) or simple reaction at $400^{\circ} \mathrm{C}$ for $100 \mathrm{~h}(120-400-6000)$. The measurements were performed with an applied DC field of $10 \mathrm{mT}$.

\section{Table caption}

Table 1: Details of heat treatments and composition determined by EDS over large areas (40.000 $\mu \mathrm{m}^{2}$ ) after the end of the reaction. 


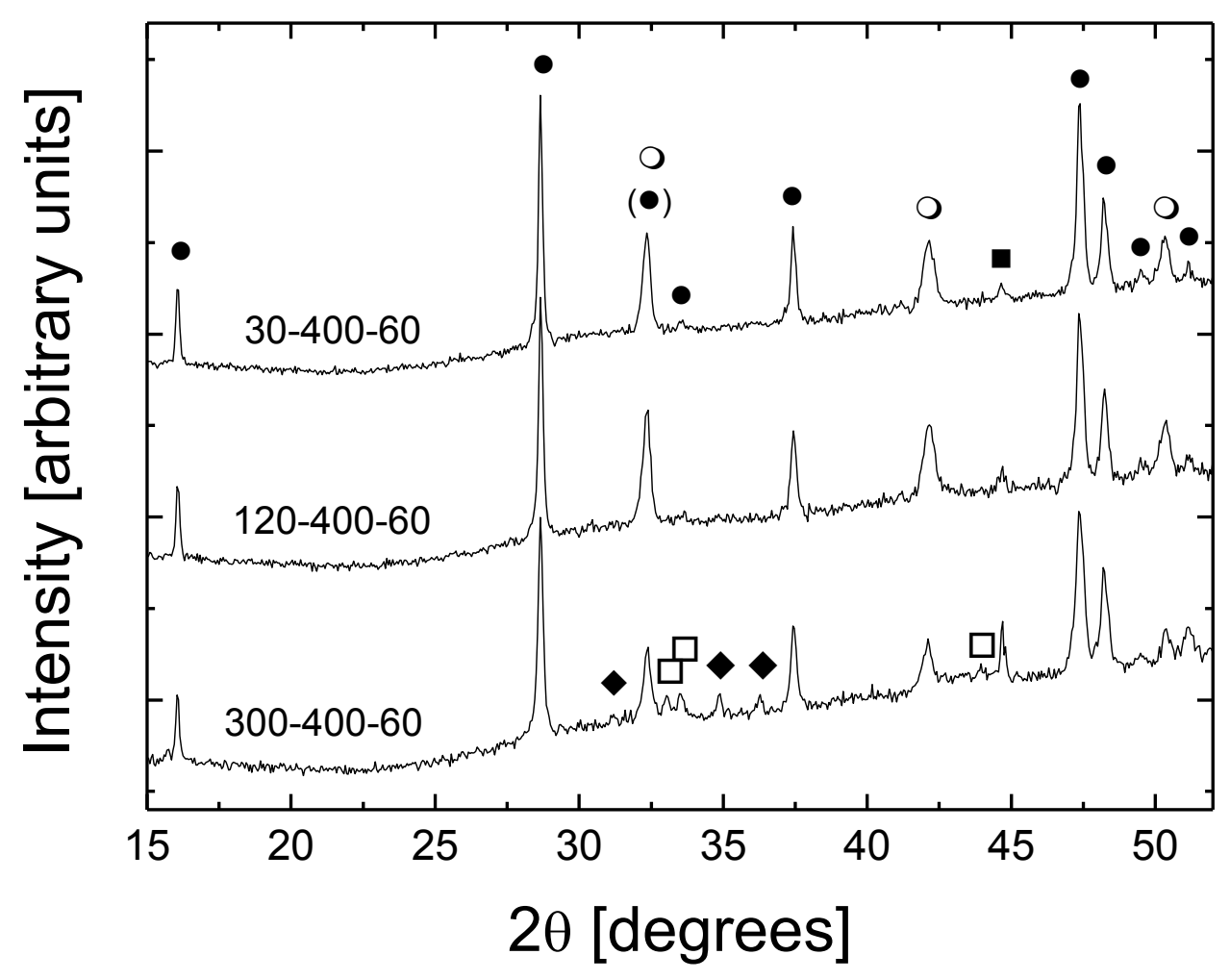

Figure 1 


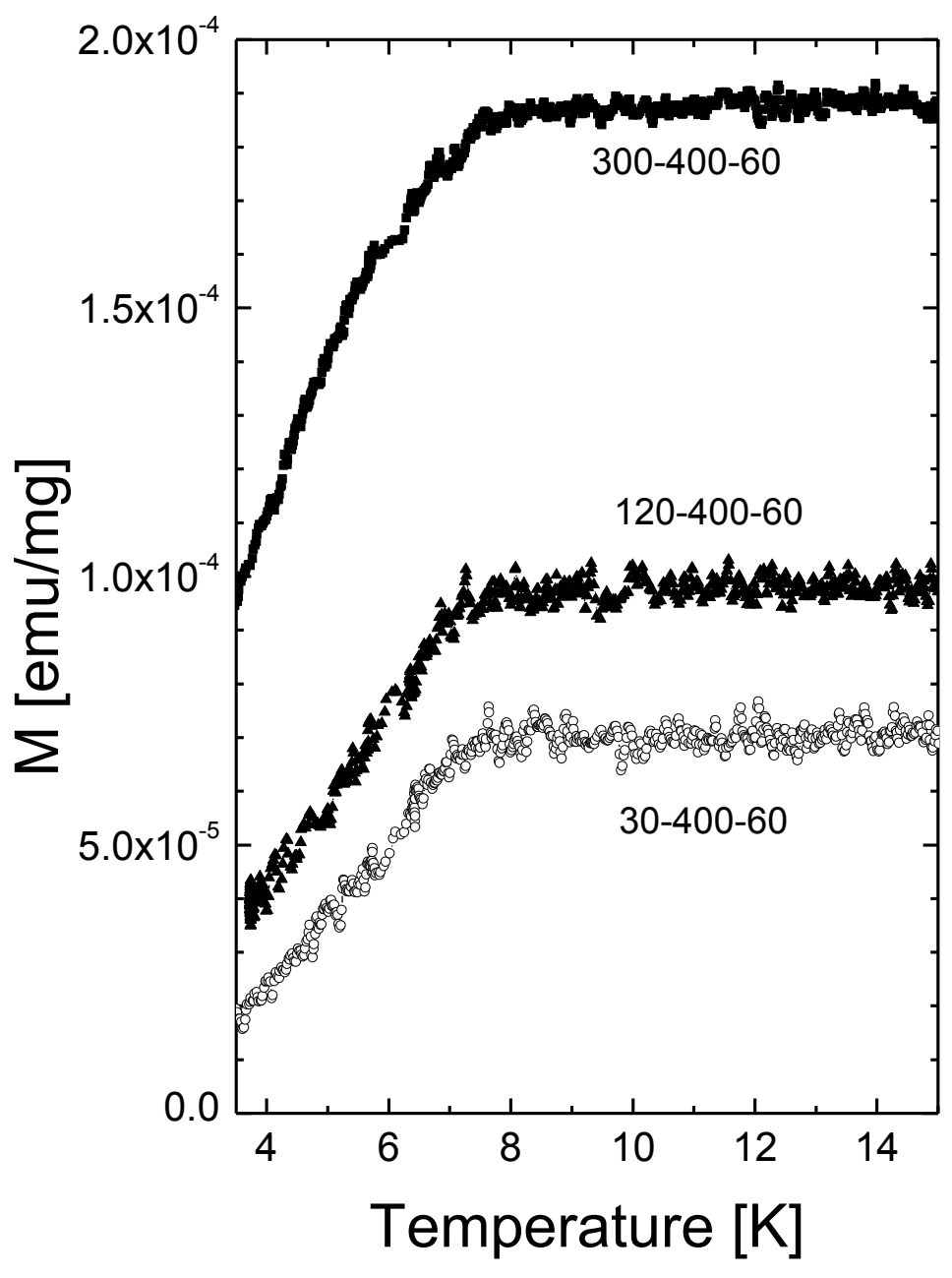

Figure 2 

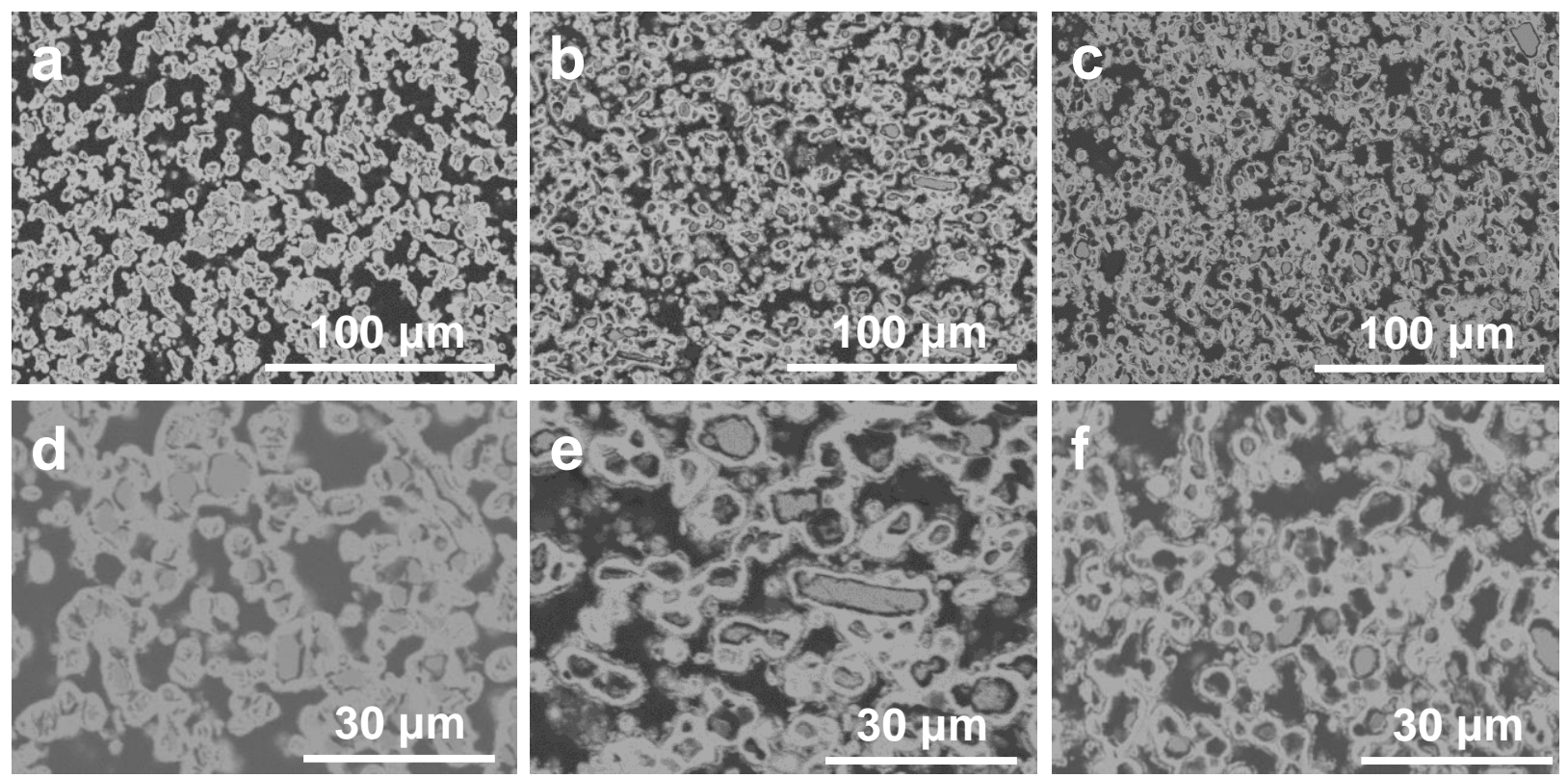

Figure 3
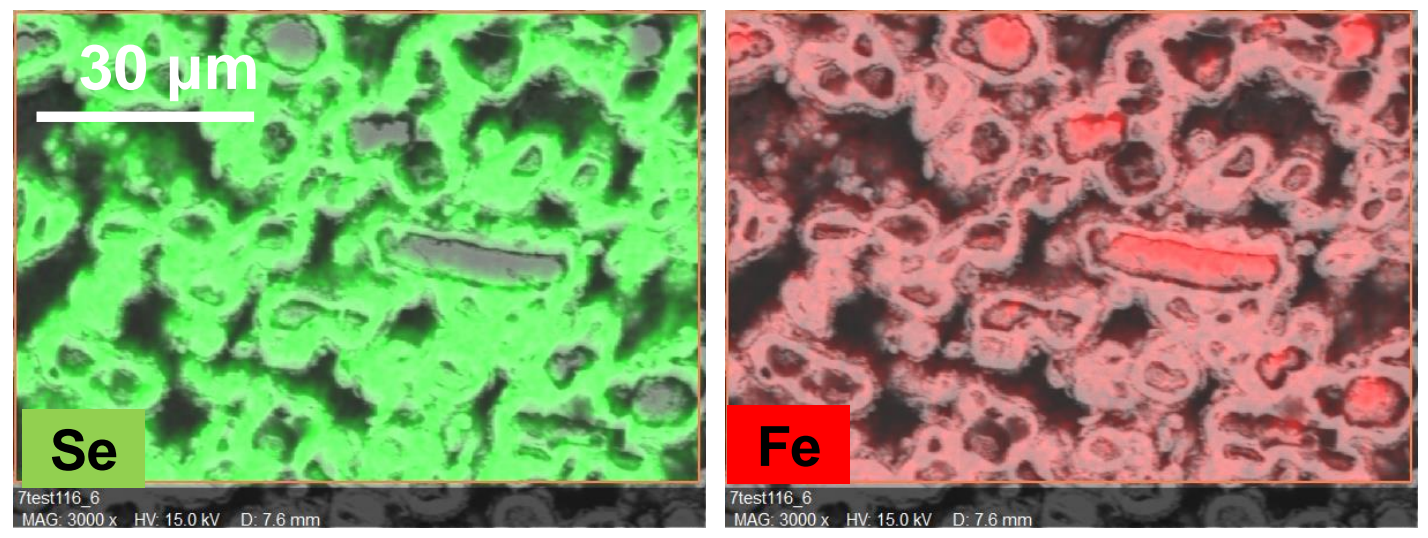

Figure 4 


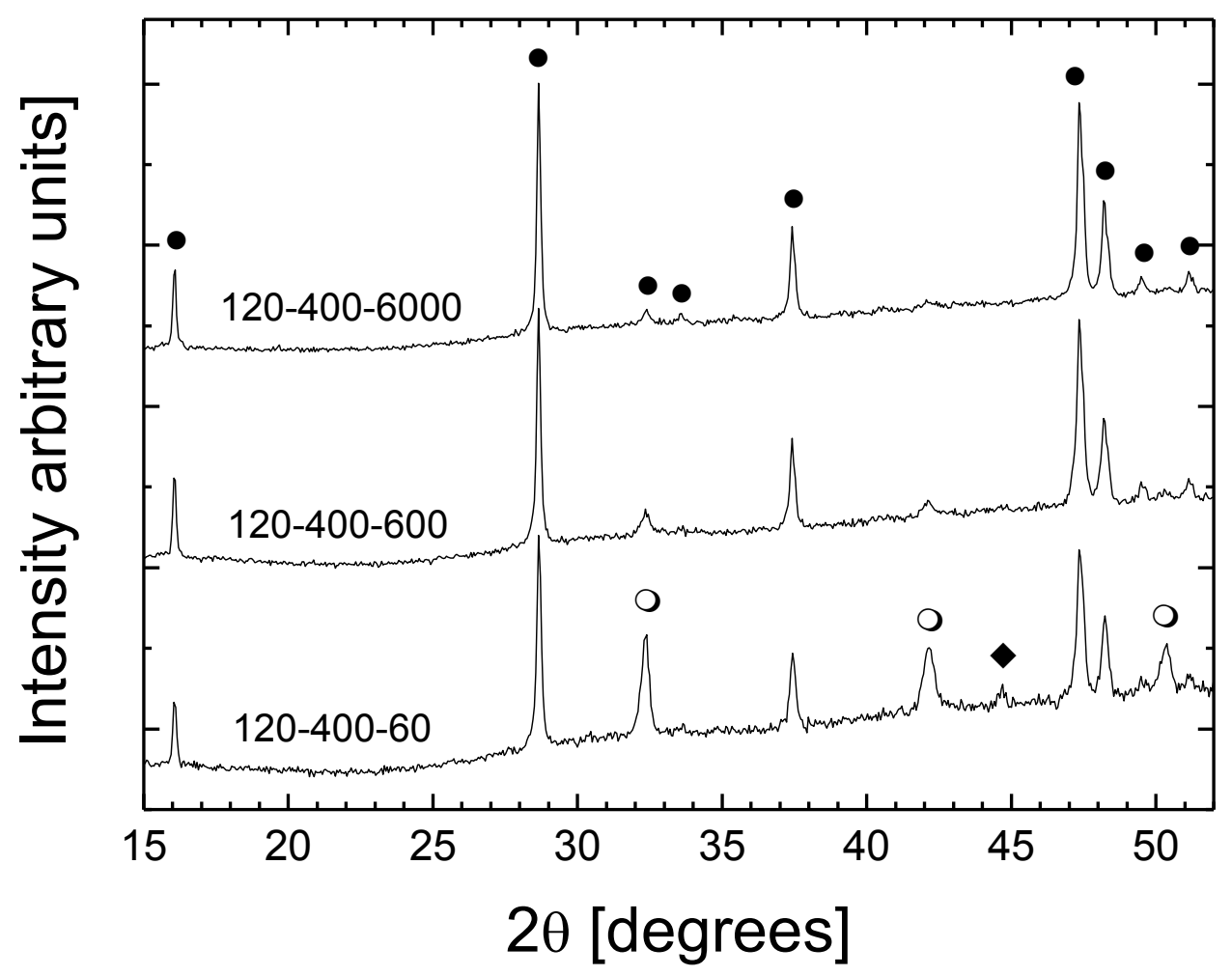

Figure 5 


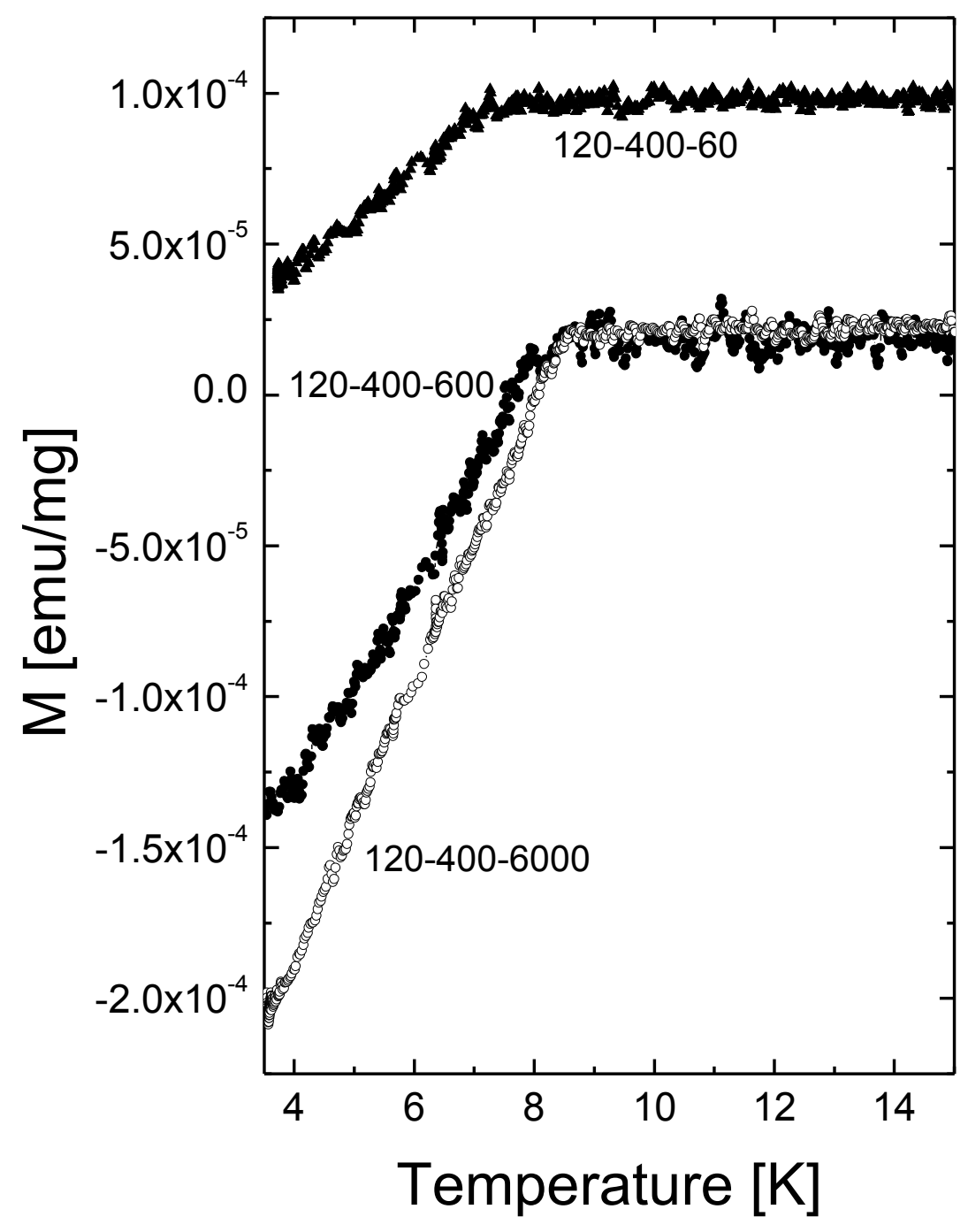

Figure 6 

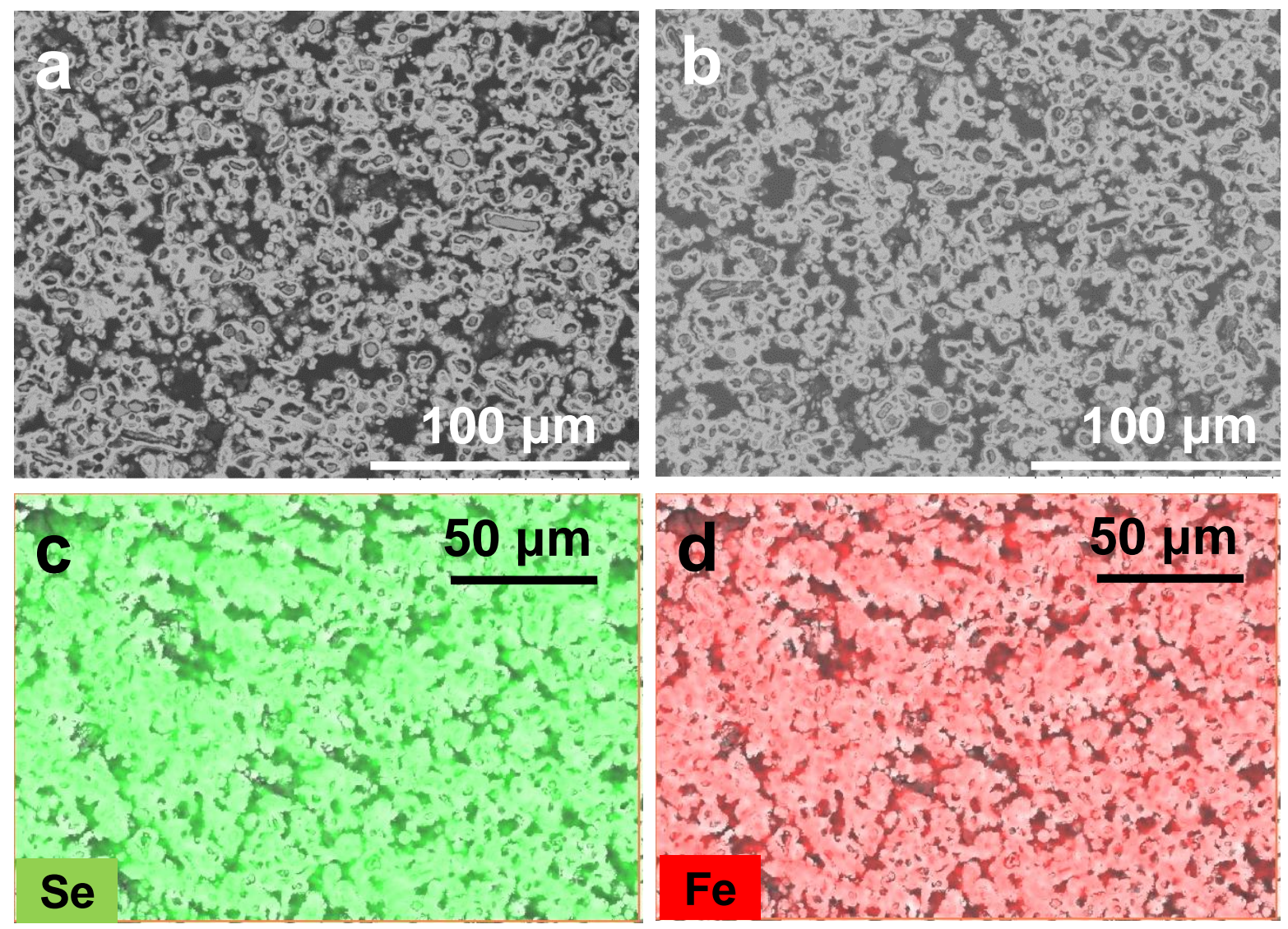

Figure 7 


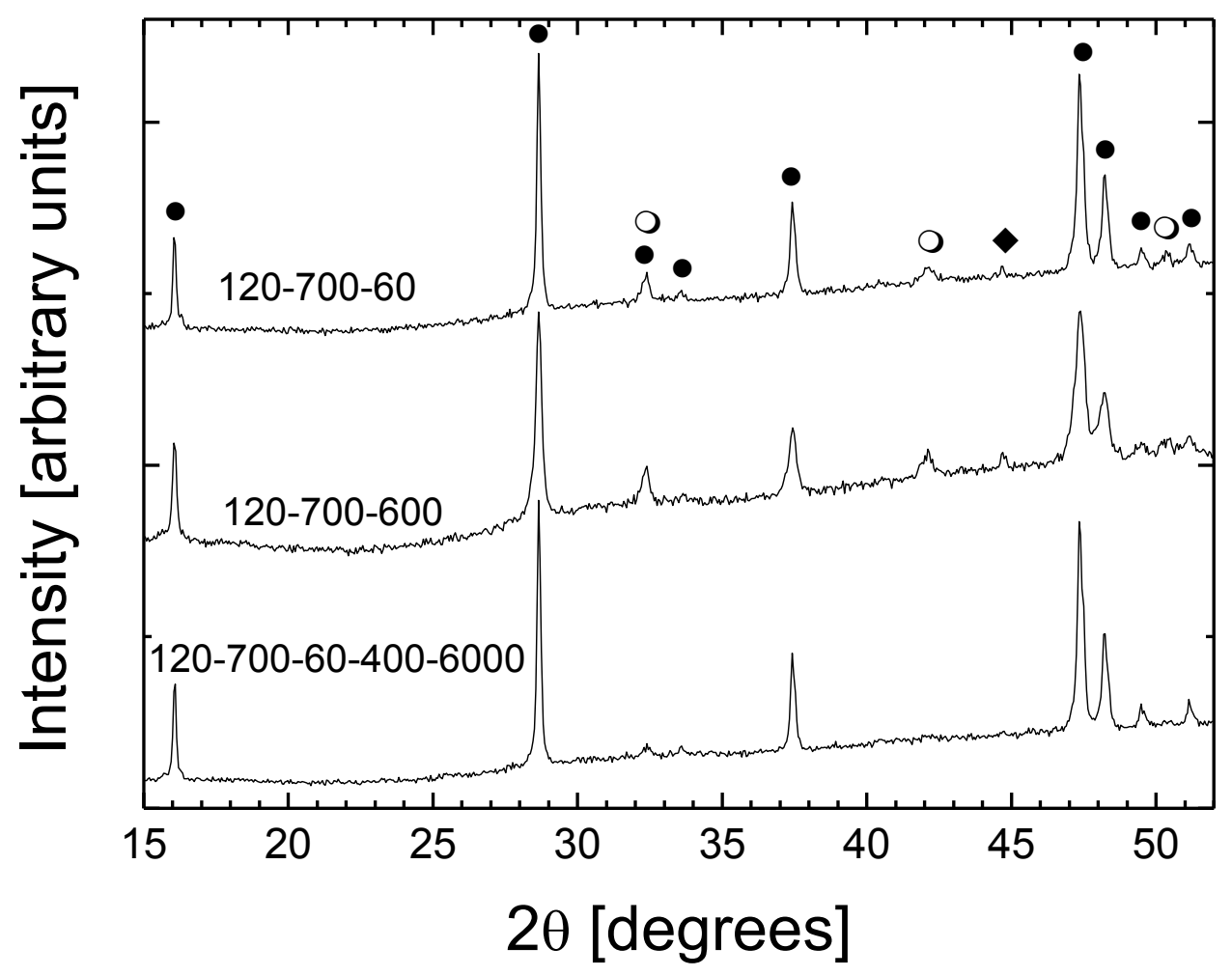

Figure 8 


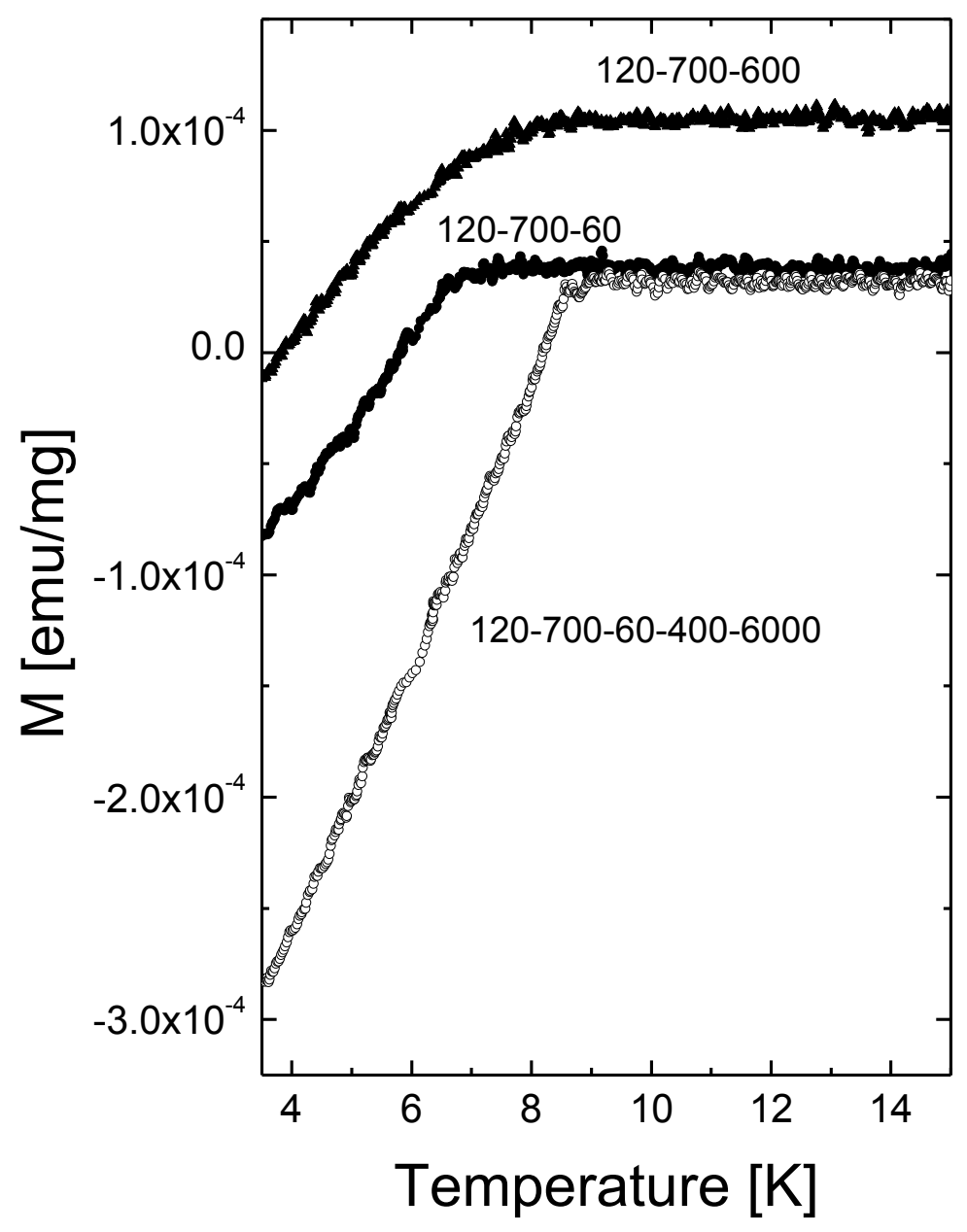

Figure 9 


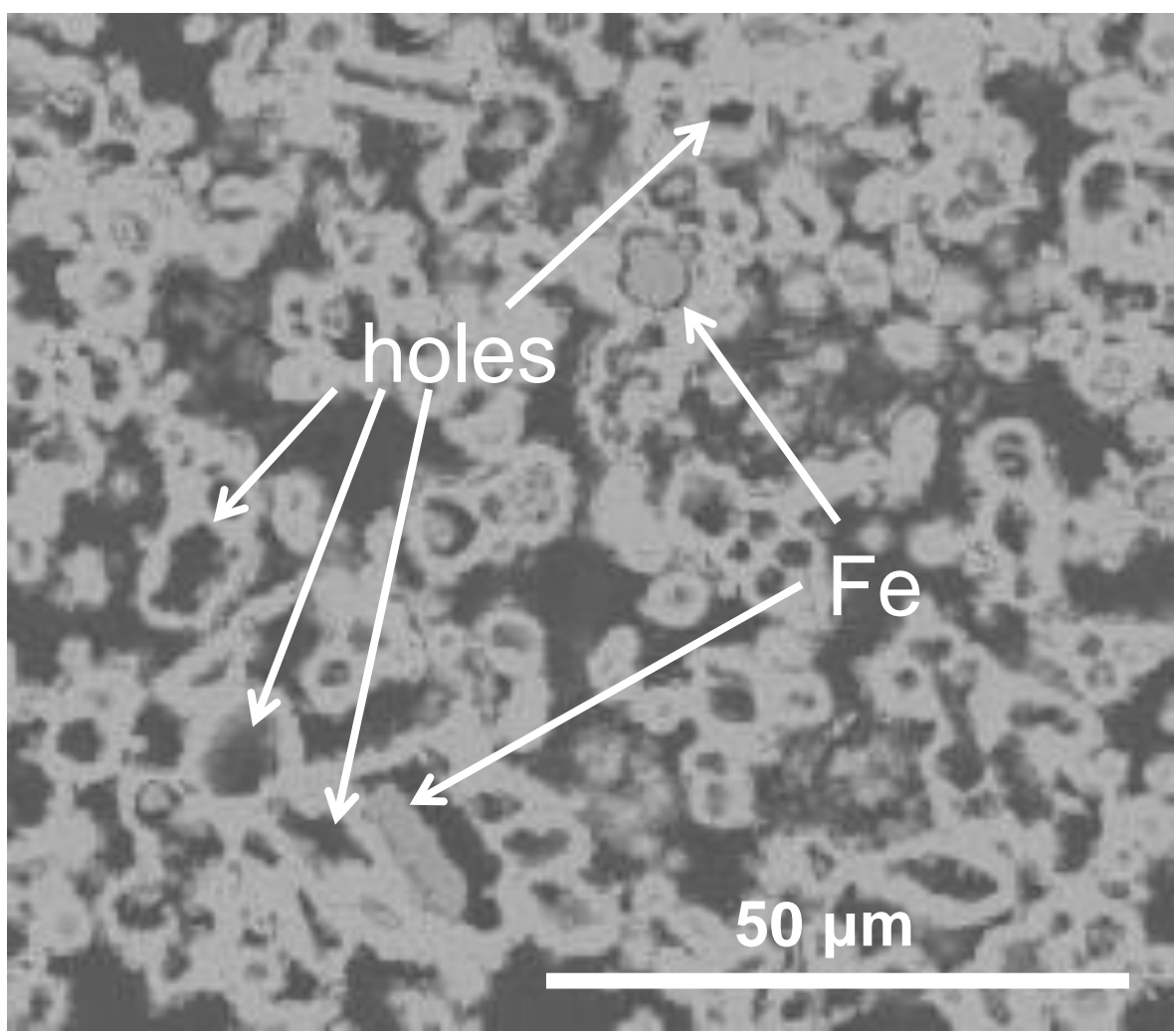

Figure 10
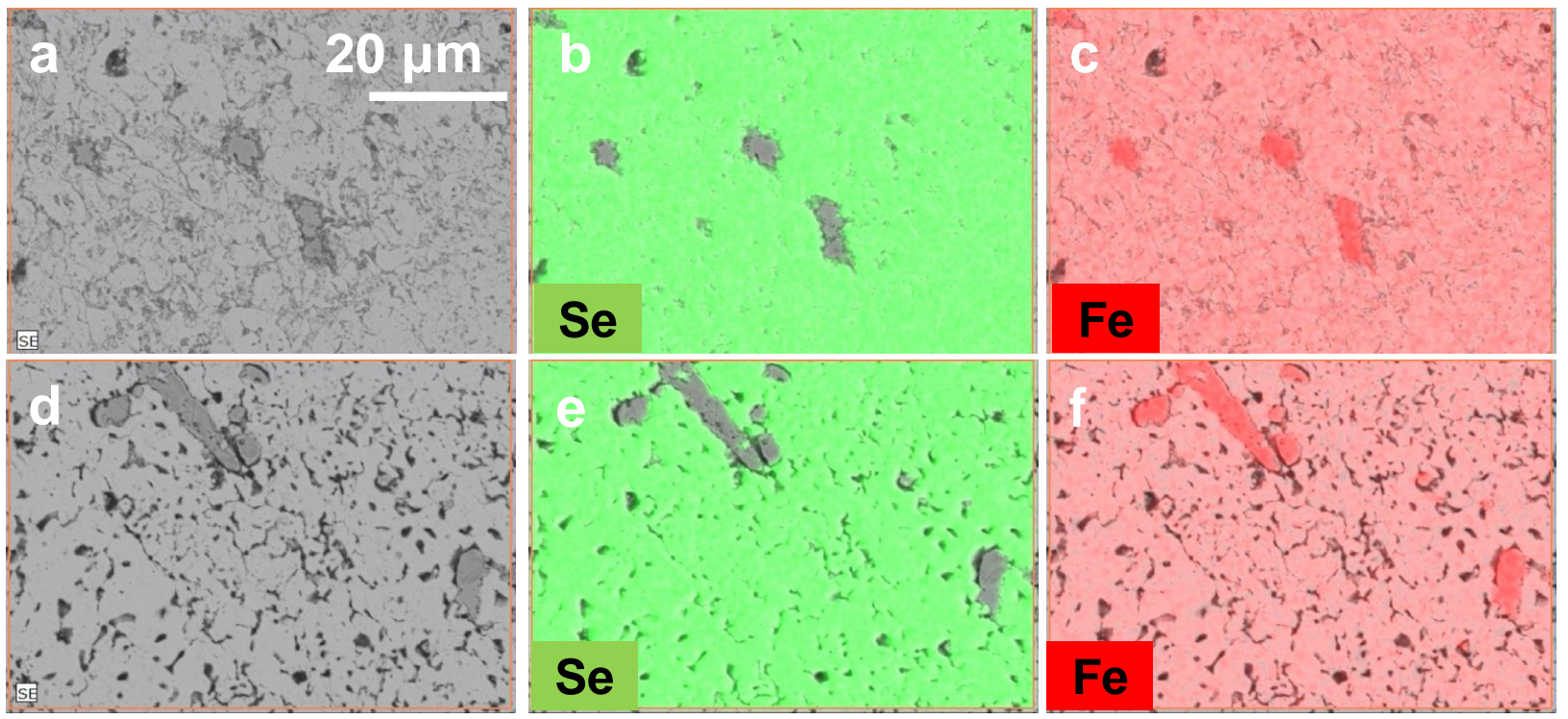

Figure 11 


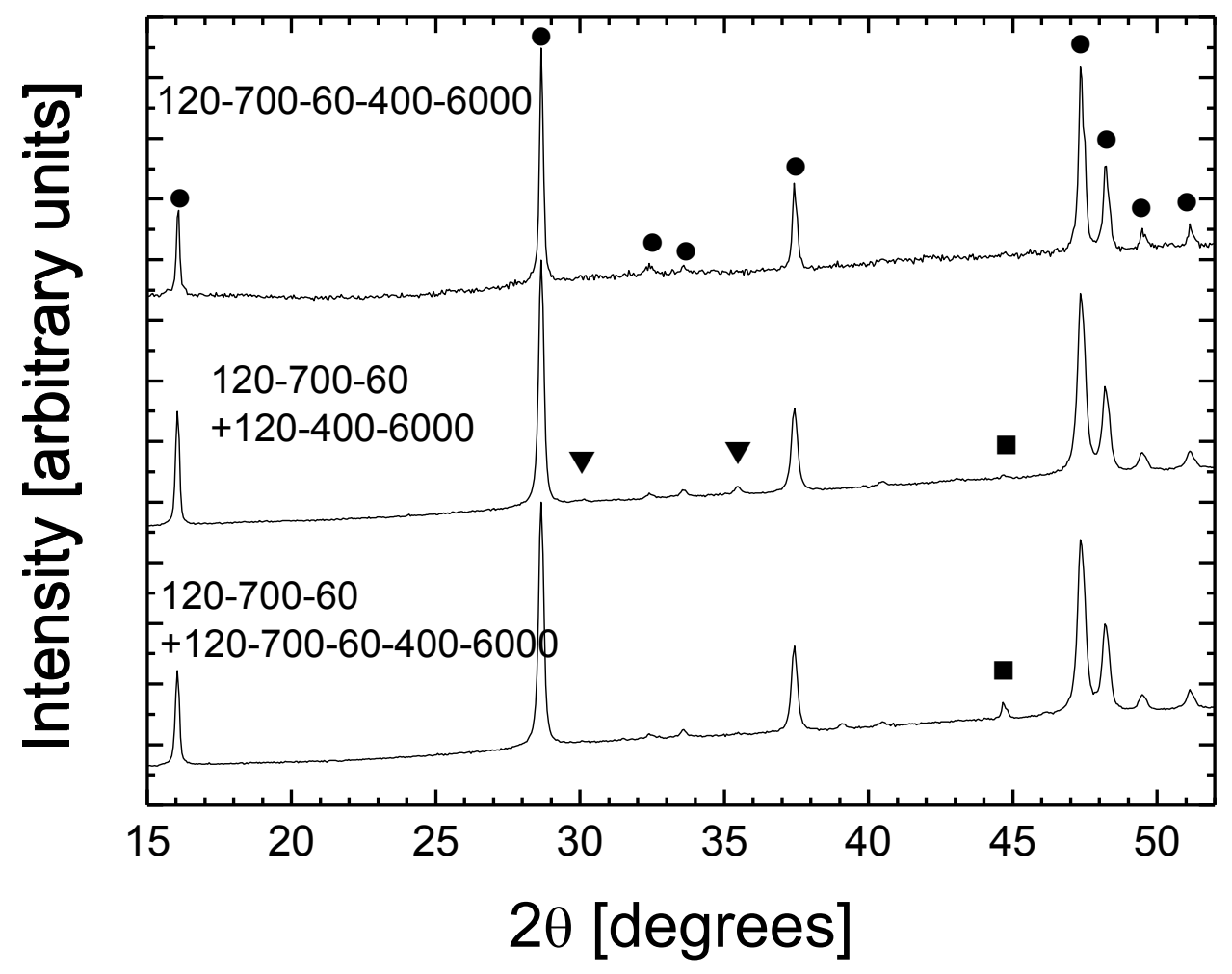

Figure 12 


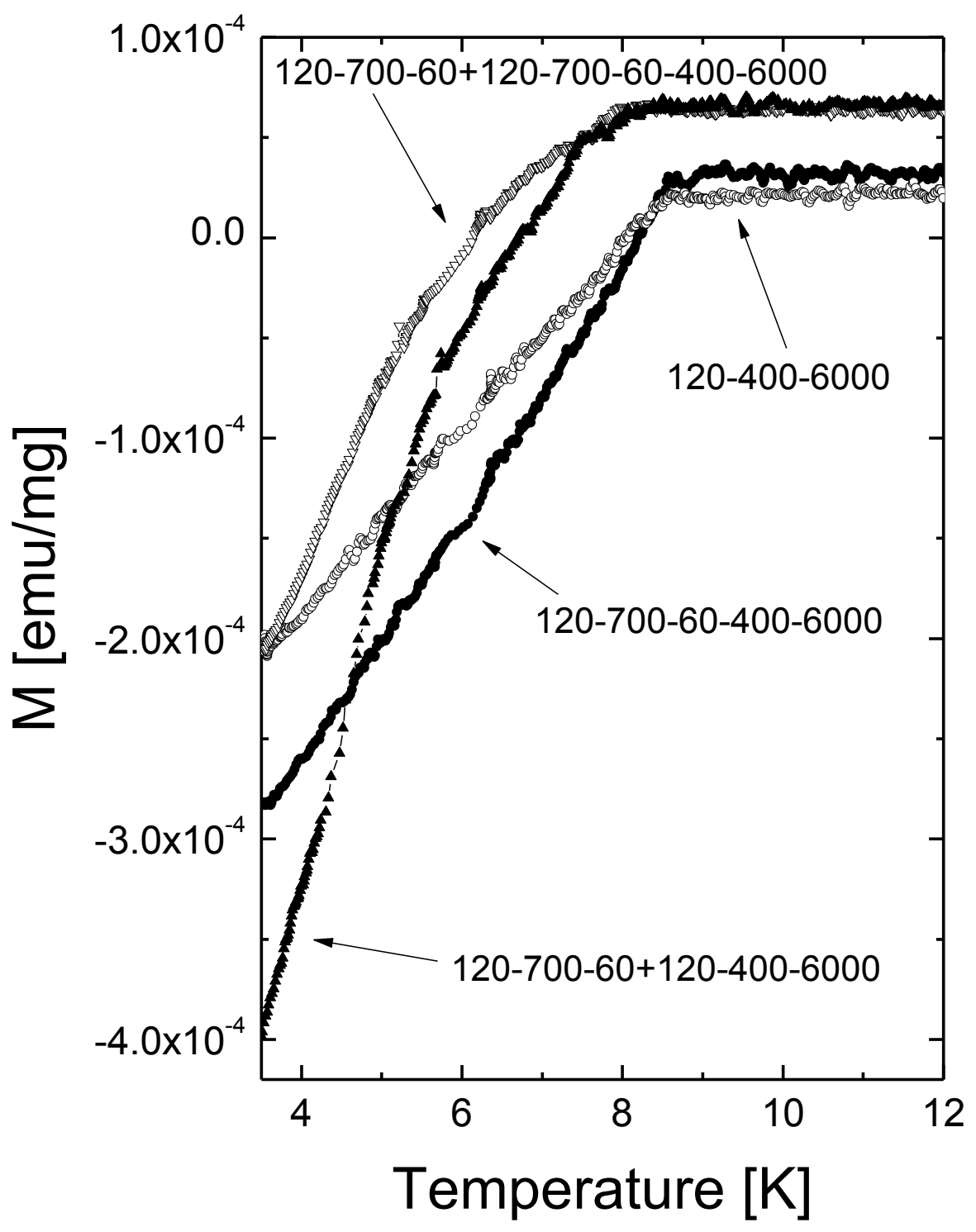

Figure 13 


\begin{tabular}{|c|c|c|c|c|c|}
\hline Sample & $\begin{array}{l}\text { Heating rate } \\
\qquad\left[{ }^{\circ} \mathrm{C} / \mathrm{h}\right]\end{array}$ & $\begin{array}{l}\mathrm{T}_{\text {react }} \\
{\left[{ }^{\circ} \mathrm{C}\right]}\end{array}$ & $\begin{array}{c}\text { Duration } \\
\text { [h] }\end{array}$ & Annealing step & $\begin{array}{l}\mathrm{x} \text { in } \mathrm{FeSe}_{\mathrm{x}} \\
2 \% \text { relative } \\
\text { accuracy) }\end{array}$ \\
\hline $300-400-60$ & 300 & 400 & 1 & no & 0.98 \\
\hline $120-400-60$ & 120 & 400 & 1 & no & 0.99 \\
\hline $30-400-60$ & 30 & 400 & 1 & no & 0.84 \\
\hline $120-400-600$ & 120 & 400 & 10 & no & 0.99 \\
\hline $120-400-6000$ & 120 & 400 & 100 & no & 0.98 \\
\hline $120-700-60$ & 120 & 700 & 1 & no & 0.98 \\
\hline $120-700-600$ & 120 & 700 & 10 & no & 0.87 \\
\hline $120-700-60-400-6000$ & 120 & 700 & 1 & $400^{\circ} \mathrm{C} / 100 \mathrm{~h}$ & 0.97 \\
\hline $120-700-60+120-400-6000$ & 120 & 700 & 1 & $400^{\circ} \mathrm{C} / 100 \mathrm{~h}$ & 0.97 \\
\hline $120-700-60+120-700-60-400-6000$ & 120 & 700 & 1 & $700^{\circ} \mathrm{C} / 1 \mathrm{~h}+400^{\circ} \mathrm{C} / 100 \mathrm{~h}$ & 0.95 \\
\hline
\end{tabular}

Table 1 